\title{
The neuropsychology of the schizo-obsessive subtype of schizophrenia: a new analysis
}

\author{
D. D. Patel ${ }^{1}$, K. R. Laws ${ }^{1 *}$, A. Padhi ${ }^{3}$, J. M. Farrow ${ }^{3}$, K. Mukhopadhaya ${ }^{3}$, R. Krishnaiah ${ }^{3}$ \\ and N. A. Fineberg ${ }^{2,3}$ \\ ${ }^{1}$ School of Psychology, University of Hertfordshire, UK \\ ${ }^{2}$ Postgraduate Medical School, University of Hertfordshire, UK \\ ${ }^{3}$ National OCDs Specialist Service, Herts. Partnership NHS Foundation Trust, Queen Elizabeth II Hospital, Welwyn Garden City, Herts, UK
}

Background. Interest in the neuro-cognitive profile of patients with schizophrenia and co-morbid obsessive compulsive disorder (schizo-OCD) is rising in response to reports of high co-morbidity rates. Whereas schizophrenia has been associated with global impairment in a wide range of neuro-cognitive domains, OCD is associated with specific deficits featuring impaired performance on tasks of motor and cognitive inhibition involving frontostriatal neurocircuitry.

Method. We compared cognitive function using the CANTAB battery in patients with schizo-OCD $(n=12)$ and a schizophrenia group without OCD symptoms $(n=16)$. The groups were matched for IQ, gender, age, medication, and duration of illness.

Results. The schizo-OCD patients made significantly more errors on a task of attentional set-shifting (ID-ED set-shift task). By contrast, no significant differences emerged on the Stockings of Cambridge task, the Cambridge Gamble Task or the Affective Go/NoGo tasks. No correlation emerged between ID-ED performance and severity of schizophrenia, OCD or depressive symptoms, consistent with neurocognitive impairment holding trait rather than statemarker status. Schizo-obsessives also exhibited a trend toward more motor tics emphasizing a neurological contribution to the disorder.

Conclusion. Our findings reveal a more severe attentional set-shifting deficit and neurological abnormality that may be fundamental to the neuro-cognitive profile of schizo-OCD. The clinical implications of these impairments merit further exploration in larger studies.

Received 10 December 2008; Revised 23 July 2009; Accepted 6 August 2009; First published online 12 October 2009

Key words: Endophenotype, frontal lobes, obsessive-compulsive, set-shifting.

\section{Introduction}

The term 'schizo-obsessiveness' was coined by Hwang \& Opler (1994) and refers to a dual diagnosis of schizophrenia and obsessive compulsive disorder (OCD) or obsessive compulsive symptoms (OCS). Although large variance exists in the documented prevalence rates of schizo-obsessive disorder, higher-thanexpected co-morbidity rates for OCD and schizophrenia have ignited a controversy (Huppert \& Smith, 2005). The prevalence of OCD in the general population remains quite controversial; however, it is certainly much lower (with estimates from 0.08 to $2.5 \%$; e.g. Fireman et al. 2001; Crino et al. 2005) than the prevalence of OCD in schizophrenia, which has

* Address for correspondence: Professor K. R. Laws, School of Psychology, University of Hertfordshire, Hatfield AL10 9AB, UK.

(Email: k.laws@herts.ac.uk) estimates ranging from 0.5 to $59.2 \%$ both in firstepisode and in chronic schizophrenia (Bland et al. 1987; Karno et al. 1988; Berman et al. 1995; Eisen et al. 1997; Poyurovsky et al. 1999a, 2000, 2003, 2006; Bermanzohn et al. 2000; Kruger et al. 2000; Niehaus et al. 2005; Mukhopadhaya et al. 2009) and for OCS in schizophrenia the estimated prevalence is similarly between 3.5 and 46\% (Rosen, 1957; Myers et al. 1984; Fenton \& McGlashan, 1986; Berman et al. 1995, 1998; Lysaker et al. 2000; Tibbo et al. 2000; Fabisch et al. 2001). It remains unclear if this reflects a true comorbidity, more severe illness or perhaps a unique diagnostic subcategory of schizophrenia.

A distinct neuro-anatomical profile has also been associated with schizophrenia and co-morbid OCD (schizo-OCD). Magnetic resonance imaging studies have identified significantly reduced volumes in the left hippocampus, frontal lobes (Aoyama et al. 2000) and anterior horn of the lateral and third ventricle 
(Goldstein et al. 1999) for schizophrenia patients with OCS when compared with their schizophrenia counterparts without OCS. Additionally, schizo-obsessive patients show more neurological signs (Sevincok et al. 2004), motor symptoms including catatonia, loss of motor ability or hyperactive motor activity (Tibbo et al. 2000) and extrapyramidal symptoms (Kruger et al. 2000; Ohta et al. 2003; Mukhopadhaya et al. 2009) compared with schizophrenia subjects; and more tics when compared with patients with OCD (Poyurovsky et al. 2006). However, not all studies have found more neurological or motor symptoms in schizo-OCD compared with OCD (Poyurovsky et al. 2007). Schizophrenia patients with OCS have higher levels of positive and emotional discomfort symptoms on the Positive and Negative Syndrome Scale (PANSS) compared with patients without OCS (Hwang et al. 2000; Lysaker et al. 2000; Tibbo et al. 2000), they tend to have a poorer prognosis (Fenton and McGlashan, 1986), poorer treatment outcomes (Lysaker et al. 2004) and more severe impairment of social functioning (Poyurovsky et al. 2001; Lysaker et al. 2004). Although, not all studies have found a poorer prognosis in terms of global functioning and illness severity (Rajkumar et al. 2008) or more positive and negative symptoms on the PANSS compared with patients without OCD (Byerly et al. 2005; Poyurovsky et al. 2006; Rajkumar et al. 2008). With the addition of selective serotonin reuptake inhibitors (SSRIs), symptoms such as agitation and psychosis have been observed in schizoobsessives (Lindenmayer et al. 1990; Zohar et al. 1993; Berman et al. 1995; Bermanzohn et al. 1997; Poyurovsky et al. 1999b) suggesting that in this subgroup the symptoms of OCD may be more difficult to treat with pharmacotherapy. Furthermore, Mukhopadhaya et al. (2009) reported that schizo-OCD cases treated with SSRIs showed greater levels of extra-pyramidal side effects compared with untreated counterparts. Finally, schizo-obsessives are greater health service users compared with subjects with schizophrenia (Berman et al. 1995) and have a longer duration of hospitalizations (Fenton \& McGlashan, 1986; Berman et al. 1995; Hwang et al. 2000). Clarification of the neuro-biological status of schizo-OCD may prompt modification of existing treatment strategies or even the development of new targeted treatments for this prominently disabled group.

Neuropsychological assessment using standardized neuro-cognitive tasks with well understood neural underpinnings may be one way of evaluating the different neural contributions to schizophrenia with OCD. Patients with schizophrenia show deficits relative to controls across a wide range of neuropsychological domains including memory, language, attention and executive function (Fioravanti et al.
2005). The Cambridge Automated Neuropsychological Test Battery (CANTAB) is a well-established computerized neuropsychological touch-screen test battery that examines a range of neuro-cognitive functions, including tests tapping the frontal lobes and their subcortical connections. To date no published literature exists on the use of CANTAB in schizo-OCD; however, patients with 'schizophrenia only' and 'OCD only' have been found to be impaired on tasks derived from the CANTAB (see Table 1), implying this battery has utility in evaluating this patient group.

The intra- and extra-dimensional (ID-ED) phases of the ID-ED set-shift test assess reversal learning and set-shifting respectively. In humans, the former task is thought to depend upon the integrity of orbitofrontal neuro-circuitry and, the latter, ventro-lateral prefrontal cortex circuits (Hampshire \& Owen 2006). Compared with healthy controls, patients with schizophrenia exhibit significant deficits that include high levels of perseverative errors on both elements of the task (Elliott et al. 1998; Tyson et al. 2004; Ceaser et al. 2008). The Stockings of Cambridge (SOC; computerized version of Tower of London) task assesses planning and thinking and is thought to involve the dorsolateral prefrontal cortex. Patients with schizophrenia typically make fewer perfect solutions and more moves on the SOC task (Pantelis et al. 1997; Elliott et al. 1998; Hutton et al. 1998; Tyson et al. 2004; Braw et al. 2008). The Cambridge Gamble Task (CGT) of decision making and impulsivity is sensitive to the integrity of orbitofrontal neuro-circuitry (Rahman et al. 1999; Rogers et al. 1999; Murphy et al. 2001). Patients with schizophrenia exhibit longer decision-making latencies and poorer decision making (Hutton et al. 2002). The Affective Go/NoGo (AGN) task is also sensitive to orbitofrontal cortex function and assesses informationprocessing biases for positive and negative stimuli and response inhibition (Murphy et al. 1999). We are not aware of any studies that have used the AGN task in patients with schizophrenia (for a review of the use of CANTAB in schizophrenia, see Levaux et al. 2007). The specificity of the purported relationships between task performance and the frontal lobes requires further examination in schizophrenia using imaging techniques. However, a meta-analytic review of imaging studies has confirmed the presence of 'hypofrontality' in schizophrenia patients, both for resting and cognitive challenge studies (see Hill et al. 2004).

OCD patients also show impaired performance on tasks associated with frontostriatal function. On the ID-ED set-shift task, deficits have been reported both on the intra- (Veale et al. 1996; Purcell et al. 1998a) and extra-dimensional set-shift phases (Veale et al. 1996; Chamberlain et al. 2006a). In the study by Chamberlain et al. (2007b), extra-dimensional (ED) impairment was 
unrelated to symptom severity and endured despite treatment. Moreover, non-affected relatives exhibited the same abnormalities, suggesting a trait marker reflecting genetic vulnerability to OCD. Chamberlain et al. $(2007 b)$ proposed that the inability to shift attentional focus may result in cognitive inflexibility and contribute to the generation of compulsive symptoms. Purcell et al. $(1998 a, b)$ found that compared with controls, OCD patients spent more time engaged in movements on the SOC test, suggesting motor initiation and execution problems, but they showed no increase in thinking latencies nor increased error rates. In contrast, Veale et al. (1996) reported that OCD patients spend more time generating alternative strategies following an incorrect move on the same task. Similarly, Chamberlain et al. (2007a) found the OCD group made more attempts to correct solution on the SOC task. A functional magnetic resonance imaging (fMRI) study using the SOC found poorer planning in OCD patients, which was associated with decreased dorsolateral prefrontal cortex and caudate nucleus activity when compared with controls (van den Heuvel et al. 2005). Unlike patients with schizophrenia, however, individuals with OCD do not exhibit abnormal performance on the CGT (Watkins et al. 2005; Chamberlain et al. 2007a), although they make more omission errors for sad words than matched controls, suggesting a selective attentional bias toward negative stimuli (Chamberlain et al. 2007a).

Given the literature outlined above, we might expect that compared with patients with schizophrenia, schizo-obsessive patients would perform significantly poorer on tasks tapping frontostriatal function (known to be impaired in OCD such as the ID-ED and SOC tests). We also expected to find no differences between schizo-obsessives and schizophrenics on tasks linked to orbitofrontal function (such as the CGT and AGN tests). Our secondary aim was to investigate if the degree of cognitive impairment correlated with clinical measures. Consistent with neuro-cognitive impairment holding trait rather than state marker status, we hypothesized that no correlation would emerge with severity of schizophrenia, OCD or depressive symptoms. Nonetheless, we did expect a positive correlation between neuro-cognitive impairment and severity of neurological signs as we hypothesized that the latter also represented a trait marker of illness.

\section{Method}

\section{Participants}

A total of 28 patients (22 male, six female) with a primary DSM-IV diagnosis of schizophrenia were recruited from a local National Health Service Trust. The patients were aged between 20 and 67 years [mean 37.7 , standard deviation (S.D.) $=11.7]$. All had chronic schizophrenia and were medicated with the atypical antipsychotic clozapine. Patients who were unable to give informed consent or had current alcohol or illicit drug dependence or a history of head injury were specifically excluded. The 28 patients were categorized into two groups based on diagnosis using the Mini International Neuropsychiatric Inventory (MINI; Sheehan et al. 1998) and careful screening for OCS by a psychiatrist experienced in the recognition and treatment of OCD using a detailed clinical interview supplemented by the Yale Brown Obsessive Compulsive Scale and Checklist (YBOCS; Goodman et al. 1989a,b). Patients who formed the schizo-OCD group $(n=12)$ fulfilled DSM-IV criteria for schizophrenia and OCD; the remaining 16 patients had only a DSM-IV diagnosis of schizophrenia. The study was approved by the local ethics committee and all participants gave written consent to participate.

\section{Clinical measures}

All participants were administered the following clinical scales: MINI (Sheehan et al. 1998); YBOCS (Goodman et al. 1989a,b); Clinical Global Impression Scale for schizophrenia (CGI-Sch; Haro et al. 2003); Sheehan Disability Scale (SDS; Sheehan et al. 1996) and the Montgomery-Åsberg Depression Rating Scale (MADRS; Montgomery \& Åsberg, 1979).

Neurological measures included: Abnormal Involuntary Movement Scale (AIMS; Guy, 1976) ; Simpson Angus Scale (SAS; Simpson \& Angus, 1970); Neurological Evaluation Scale (NES; Buchanan and Heinrichs, 1989); Yale Global Tic Severity Scale (YGTSS; Leckman et al. 1989), Meta-cognition Questionnaire (MCQ-30; Wells \& Cartwright-Hatton, 2004).

The MCQ-30 measures individual differences in a selection of meta-cognitive beliefs, judgements and monitoring tendencies.

\section{Neuropsychological measures}

Patients were administered the National Adult Reading Test (NART) (Nelson, 1982) and four tests from the CANTAB (see below), two of which were chosen to evaluate neuro-cognitive functioning believed to depend upon frontostriatal neuro-circuitry (ID-ED, SOC) and two to measure neuro-cognitive function subserved by orbitofrontal circuits (CGT, AGN). The order of the neuropsychological tasks was counterbalanced in each group.

Intra-extra dimensional set-shift task. During the conceptually crucial extra-dimensional shift (EDS) stage, 
Table 1. Neuropsychological performance on $C A N T A B$ tests in patients with schizophrenia and OCD

\begin{tabular}{|c|c|c|c|c|}
\hline \multirow[b]{2}{*}{ Task } & \multicolumn{2}{|c|}{ Schizophrenia $v$. Control } & \multicolumn{2}{|l|}{ OCD v. Control } \\
\hline & Author & Findings & Author & Findings \\
\hline \multirow[t]{9}{*}{ ID-ED } & Elliott et al. 1995 & More perseverative errors & Veale et al. 1996 & More failures at each stage \\
\hline & Pantelis et al. 1999 & More errors at IDS and EDS & Purcell et al. 1998a & IDS lower score \\
\hline & $\begin{array}{l}\text { Shamay-Tsoory et al. } \\
2007\end{array}$ & $\begin{array}{l}\text { More trials to reach criterion at } \\
\text { ID reversal, EDS and ED reversal }\end{array}$ & Chamberlain et al. $2006 a$ & $\begin{array}{l}\text { More trials to reach criterion } \\
\text { on ED shift trials }\end{array}$ \\
\hline & Joyce et al. 2002 & $\begin{array}{l}75 \% \text { of patients were unable to } \\
\text { perform an EDS }\end{array}$ & Purcell et al. $1998 b$ & $\begin{array}{l}\text { No difference on IDS and EDS } \\
\text { trial scores }\end{array}$ \\
\hline & Hutton et al. 1998 & $\begin{array}{l}\text { First episode schizophrenia patients had intact } \\
\text { ability to switch attention }\end{array}$ & Nielen \& den Boer 2003 & $\begin{array}{l}\text { Require same number of trials to complete } \\
\text { the task, no difference in ID or ED errors }\end{array}$ \\
\hline & Tyson et al. 2004 & $\begin{array}{l}\text { Fewer stages reached, more errors } \\
\text { up to ED } S \text { and at EDS }\end{array}$ & Watkins et al. 2005 & $\begin{array}{l}\text { More errors at ED stage, more } \\
\text { patients failed to complete all stages }\end{array}$ \\
\hline & Jazbec et al. 2007 & $\begin{array}{l}\text { Selective difficulties on C_D and } \\
\text { EDS stages }\end{array}$ & Fenger et al. 2005 & $\begin{array}{l}\text { Deficit in shifting attention, reversing response, } \\
\text { performed more poorly on IDS and EDS trials }\end{array}$ \\
\hline & Braw et al. 2008 & $\begin{array}{l}\text { More errors, fewer stages } \\
\text { completed }\end{array}$ & Chamberlain et al. $2007 b$ & $\begin{array}{l}\text { More trials to reach criterion } \\
\text { on EDS trials }\end{array}$ \\
\hline & Elliott et al. 1998 & $\begin{array}{l}\text { More errors, more perseverative errors on EDS } \\
\text { and IDS }\end{array}$ & & \\
\hline \multirow[t]{7}{*}{ SOC } & Pantelis et al. 1997 & $\begin{array}{l}\text { More moves, fewer perfect solutions, longer to } \\
\text { execute, longer subsequent thinking time }\end{array}$ & Veale et al. 1996 & $\begin{array}{l}\text { Longer generating solutions, } \\
\text { more errors at each stage }\end{array}$ \\
\hline & Elliott et al. 1998 & $\begin{array}{l}\text { Fewer correct on higher move } \\
\text { problems }\end{array}$ & Purcell et al. 1998a & $\begin{array}{l}\text { Longer initial movement time, } \\
\text { longer subsequent movement time }\end{array}$ \\
\hline & Joyce et al. 2002 & $\begin{array}{l}\text { More failures at ED stage, reached } \\
\text { lower stages }\end{array}$ & Watkins et al. 2005 & $\begin{array}{l}\text { One touch SOC found intact } \\
\text { planning ability }\end{array}$ \\
\hline & Tyson et al. 2004 & Solved fewer minimum move problems & Purcell et al. $1998 b$ & $\begin{array}{l}\text { Longer, initial and subsequent } \\
\text { movement times }\end{array}$ \\
\hline & Braw et al. 2008 & $\begin{array}{l}\text { Longer initial thinking times, } \\
\text { longer subsequent thinking times, solved } \\
\text { fewer problems in minimum moves }\end{array}$ & Chamberlain et al. $2006 \mathrm{~b}$ & $\begin{array}{l}\text { Lower strategy scores, generated } \\
\text { fewer novel sequences after training }\end{array}$ \\
\hline & & & Pantelis et al. 1997 & $\begin{array}{l}\text { Fewer perfect solutions, required } \\
\text { more moves for completion, slower movement } \\
\text { times and slower subsequent thinking latencies }\end{array}$ \\
\hline & & & Nielen and Den Boer, 2003 & $\begin{array}{l}\text { Fewer minimum move solutions, } \\
\text { longer subsequent thinking time and longer time } \\
\text { spent initiating and completing one sequence }\end{array}$ \\
\hline
\end{tabular}




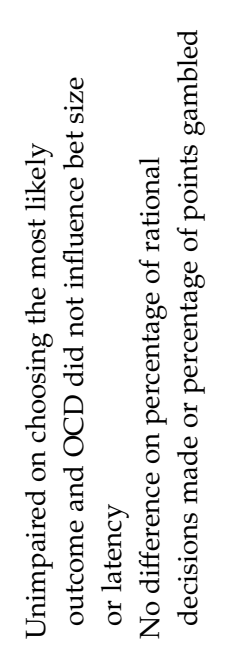

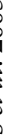

divergent thinking is required in order to shift attention away from a previously correct stimulus dimension to a novel (previously irrelevant) one. The total number of errors on the ID-ED and the number of errors at the EDS stage were used as the principal measures of attentional set-shifting.

Stockings of Cambridge. The SOC assesses spatial planning and motor control and is essentially a version of the Tower of London task. The trial evaluates executive planning that involves placing balls in sockets to match a given pattern within a specified number of moves. A low score on the measure 'number of problems solved in minimum moves' reflects an individual's inability to plan ahead.

Cambridge Gamble Task. This task assesses impulse control, risk-taking behaviour and decision making. The participant is presented with a row of boxes across the top of the screen, some of which are coloured red and others blue. Participants start by guessing whether a token is hidden in a red or blue box. In the gambling stages, subjects are given 100 points and can place a bet on the location of the token (either rising or falling offers) based on their confidence. The ratio of red:blue boxes is manipulated to present different levels of uncertainty of winning and the aim is to accumulate as many points as possible. A higher score on the CGT risk-taking measure is indicative of more risk taking. The task also measures the average latency to make the decision when placing bets.

Affective Go-NoGo Task. The AGN assesses moodprocessing bias. A series of words, either positive or negative, are rapidly presented in the middle of the screen. The participant is given a target category, e.g. positive, and is asked to respond whenever they see a word that matches the category. The AGN total omissions measure (e.g. failure to respond to sad words in sad word blocks) was used to measure response inhibition, where more errors would be indicative of motor impulsivity, i.e. an inability to inhibit motoric responses; mean correct latency was also recorded.

\section{Statistical analyses}

The distributions for all data were examined using the Kolmogorov-Smirnov statistic. Where normality could not be assumed, suitable transformations were applied (arcsine, log and square root) for proportional measures from the CGT and latency measures for the SOC and AGN tasks. All analyses were run with and without clozapine dose entered as a covariate; however, it made no difference to the pattern of results and the latter are reported here. The statistical tests were 
Table 2. Clinical characteristics in schizo-obsessive disorder and schizophrenia

\begin{tabular}{lccc}
\hline & $\begin{array}{l}\text { Schizo-obsessive } \\
\text { Mean (s.D.) }\end{array}$ & $\begin{array}{l}\text { Schizophrenia } \\
\text { Mean (s.D.) }\end{array}$ & \\
\hline Males $(n)$ & 10 & 12 & \\
Females (n) & 2 & 4 & $F<1$ \\
Age (years) & $36.0(10.7)$ & $37.9(12.7)$ & \\
Age of onset (years) & $23.3(11.1)$ & $26.1(9.6)$ & $F<1$ \\
Duration of illness (years) & $12.7(5.2)$ & $11.7(8.6)$ & $F<1$ \\
NART IQ & $103.5(5.0)$ & $103.1(6.4)$ & $F<1$ \\
Clozapine (mg) & $475.0(238.0)$ & $313.83(125.0)$ & $F=5.1$, \\
& & & $p=0.03$ \\
\end{tabular}

S.D., Standard deviation; NART, National Adult Reading Test.

Table 3. Clinical measures for schizo-obsessive and schizophrenia groups

\begin{tabular}{lccc}
\hline Clinical measures & $\begin{array}{l}\text { Schizo-obsessive } \\
\text { Mean (S.D.) }\end{array}$ & $\begin{array}{l}\text { Schizophrenia } \\
\text { Mean (s.D.) }\end{array}$ & ANOVA \\
\hline $\begin{array}{l}\text { Montgomery Åsberg Depression } \\
\text { Rating Scale }\end{array}$ & $9.64(7.77)$ & $11.00(10.73)$ & $F<1$, N.s. \\
$\begin{array}{l}\text { Sheehan Disability Scale } \\
\text { Simpson-Angus Scale }\end{array}$ & $11.63(8.40)$ & $11.50(7.50)$ & $F<1$, N.s. \\
Clinical Global Impression Scale & $2.00(2.00)$ & $2.12(2.16)$ & $F<1$, N.S. \\
$\quad$ for Schizophrenia & $3.25(1.05)$ & $2.75(1.44)$ & $F=1.3$, N.S. \\
Neurological Evaluation & $17.00(7.94)$ & $12.00(7.50)$ & $F=2.69, p=0.11$ \\
$\quad$ Scale & $8.54(6.38)$ & $5.34(2.77)$ & $Z=1.84, p=0.06$ \\
Abnormal Involuntary Movement Scale & $9.92(15.08)$ & $0.50(1.87)$ & $Z=2.6, p=0.04$ \\
Total Yale Global Tic Severity & & & \\
YBOCS & $18.0(9.6)$ & $2.43(6.8)$ & $Z=3.9, p<0.001$ \\
$\quad$ Total & $8.5(5.0)$ & $1.3(3.6)$ & $Z=3.6, p<0.001$ \\
$\quad$ Obsessions & $9.5(4.7)$ & $1.1(3.1)$ & $Z=3.9, p<0.001$ \\
$\quad$ Compulsions & & \\
\hline
\end{tabular}

ANOVA, Analysis of variance; N.s., non-significant; YBOCS, Yale Brown Obsessive Compulsive Scale and Checklist. Where variables had non-normal distributions, Mann-Whitney $U$ tests were used.

conducted with multivariate analysis of variance (MANOVA) using SPSS version 16 (SPSS Inc., USA). A conventional alpha value of 0.05 was used throughout our analysis.

\section{Results}

\section{Clinical measures}

According to the CGI-Sch, the global severity of schizophrenia was assessed as mild-moderate in both groups with no between-group differences (values are given as mean \pm s.D. $)(3.25 \pm 1.05$ v. $2.75 \pm 1.44, F=1.3$, N.S.). The YBOCS revealed a moderate severity of OCD in the schizo-OCD group when compared with the patients with schizophrenia alone (18 \pm 9.6 v. $2.4 \pm 6.7)$.
The schizo-OCD group scored significantly higher than the schizophrenia patients for both their obsessive and compulsive ratings (see Table 2). MADRS (Montgomery \& Åsberg, 1979) scores (9.64 \pm 7.77 v. $11.0 \pm 10.73$ ) indicate that neither patient group was clinically depressed. Patients with schizo-OCD were prescribed more SSRI, $50 \%$ v. $33.3 \%$, but this was not significant $\left[\chi^{2}=0.77(1)\right.$, N.s.]. Similarly, there was no difference in usage of other anti-psychotics $\left[\chi^{2}=0.13(1)\right.$, N.s. $]$, mood stabilizers $\left[\chi^{2}=0.791(1)\right.$, N.s. $]$ or anti-muscarinics $\left[\chi^{2}=0.05(1)\right.$, N.s.] between groups.

The YGTSS score was significantly higher in schizoobsessives than schizophrenia counterparts [YGTSS: $\left.F(1,25)=5.84, p<0.02, \eta_{p}^{2}=0.18\right]$. No significant differences were revealed on the MADRS, SDS, SAS or NES (see Table 3). 
Table 4. Performance on neuropsychological measures for schizo-obsessive and schizophrenia groups

\begin{tabular}{lcccc}
\hline Test & $\begin{array}{l}\text { Schizo-obsessive } \\
\text { Mean (s.D.) }\end{array}$ & $\begin{array}{l}\text { Schizophrenia } \\
\text { Mean (s.D.) }\end{array}$ & F value & Effect size \\
\hline ID-ED total errors & $34.92(8.00)$ & $23.56(13.28)$ & $F=6.86, p=0.015$ & $\eta^{2}=0.21$ \\
SOC problems solved in & $5.75(1.49)$ & $7.07(2.71)$ & $F=2.72, p=0.14$ & $\eta^{2}=0.08$ \\
minimum moves & & & \\
CGT risk taking & $0.54(0.17)$ & $0.48(0.17)$ & $F<1$, N.S. & $\eta^{2}=0.03$ \\
CGT decision latency & $4.95(3.41)$ & $4.80(2.86)$ & $F<1$, N.S. & $\eta^{2}=0.00$ \\
AGN total omissions & $30.00(28.34)$ & $33.13(28.98)$ & $F<1$, N.S. & $\eta^{2}=0.00$ \\
AGN latency & $5.12(1.13)$ & $5.69(1.16)$ & $F=1.25, p=0.28$ & $\eta^{2}=0.06$ \\
MCQ-30 total & $31.42(14.94)$ & $35.94(16.53)$ & $F<1$, N.S. & $\eta^{2}=0.02$ \\
\hline
\end{tabular}

For definitions of abbreviations, see Table 1; MCQ-30, Meta-Cognition Questionnaire.

\section{Neuropsychological differences}

A MANOVA revealed one significant group difference (see Table 4) with schizo-obsessives, making significantly more total errors on the ID-ED task $\left(F_{1,26}=6.86, p=0.015, \eta_{p}^{2}=0.21\right.$ : mean $34.92 v$. mean 23.56).

\section{Intra- and extra-dimensional performance}

To investigate which elements of the ID-ED task were more difficult for schizo-obsessives, a MANOVA was conducted to test for differences in the number of errors made at each stage of the task between the schizoobsessive and the schizophrenia groups (Fig. 1). We found a significant difference between the number of errors made specifically at the ED stage with significantly more errors made by the schizo-obsessive group $\left(F_{1,26}=4.03, p=0.05, \eta^{2}=0.13\right)$. There was no significant difference between the number of errors on the extra-dimensional shift reversal (EDSR) stage between the two groups $\left(F_{1,26}=2.96, p=0.09\right)$.

\section{Relationships between neuropsychological function and clinical symptoms}

Correlational analyses revealed no evidence of a relationship between neuro-cognitive performance on the ID-ED and measures of schizophrenia symptom severity (CGI), depression (MADRS), or OCD (YBOCS) - all $\mathrm{r}<0.2$, all N.s.

\section{Relationships between neuropsychological function and neurological symptoms}

In the schizo-obsessive group, correlational analysis revealed that increased severity of motor tics, as measure $\mathrm{d}$ by the YGTSS, positively correlated with CGT decision latency $(r=0.65, n=11, p=0.03)$. There was no further evidence of a relationship between neuro-cognitive measures (ID-ED, SOC, CGT, AGN)
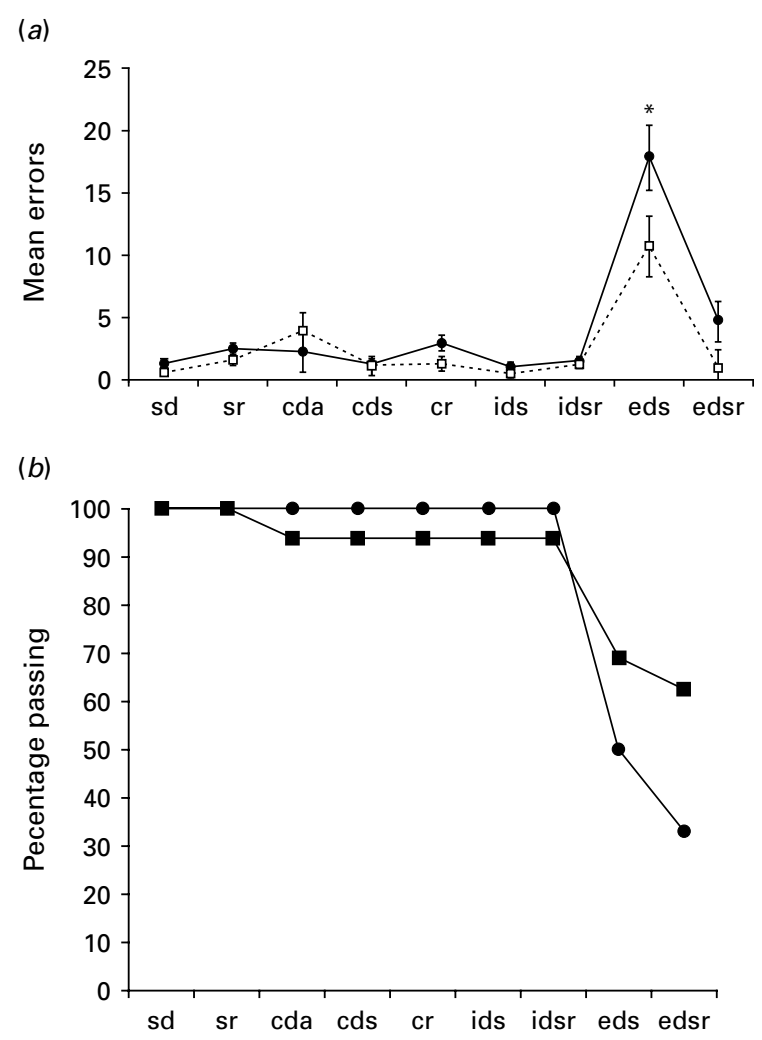

Fig. 1. (a) Mean intra- and extra-dimensional errors on each block for schizo-obsessive (sz-obs ; --) and schizophrenia (sz; - - - $\square$ - - -) groups (error bars are standard error);

(b) percentage of sz-obs $\left(-\bullet_{-} ; n=12\right)$ and sz $(-\boldsymbol{\square}-; n=16)$ patients passing each stage of the intra- and extradimensional task. sd, simple discrimination; sr, simple reversal; cda, compound discrimination adjacent; cds, compound discrimination superimposed; $\mathrm{cr}$, compound reversal; ids, intra-dimensional shift; idsr, intra-dimensional shift reversal; eds, extra-dimensional shift; edsr, extra-dimensional shift reversal.

and neurological measures (YGTSS, SAS, Barnes Akathisia Determination Scale, AIMS) in either group. 


\section{Discussion}

As predicted, schizo-obsessive patients performed significantly poorer on the ID-ED set-shift task, which is thought to reflect frontostriatal function, though not on the SOC task, whereas no difference in performance was found between schizo-obsessives and schizophrenics on tasks thought to probe orbitofrontal function (CGT and AGN). Also, as expected, there was no correlation between ID-ED impairment and severity of schizophrenia, OCD or depressive symptoms, consistent with neuro-cognitive impairment holding trait rather than state-marker status. The two groups were well matched in terms of severity of schizophrenia, demographics, treatment and other clinical features, apart from motor tics. The absence of clinically relevant depression in either group minimized another possible confound. Thus, the observed differences in neuro-cognitive performance are probably attributable to the fact that one group had co-morbid OCD and the other did not. Motor tics were over-represented in the schizo-OCD group and were related to longer decision latencies on the CGT. We were unable to demonstrate a correlation between performance on other neuro-cognitive measures and severity of motor or neurological signs. A single significant correlation may simply reflect a chance finding. However, considering the results from the study by Watkins et al. (2005), in which patients with Tourette's syndrome showed greater impairment on decision-making tasks, compared with OCD and normal controls, such a result could have been expected and may represent a neuro-cognitive marker related to the presence of motor tics.

The patients in this study were taking clozapine, which is less likely than other antipsychotics to induce extra-pyramidal adverse effects that might confound neuro-cognitive performance. We judge that these factors are likely to have enhanced the validity and thus the generalizability of our results for this group of schizophrenia patients. Nevertheless, it is important to acknowledge that our results refer to antipsychoticresistant cases that are receiving clozapine and they therefore cannot necessarily be generalized to all cases of schizophrenia. Additionally, an intriguing literature suggests that antipsychotics may actually induce obsessive symptoms in patients with schizophrenia (see reviews by Fineberg et al. 2006; Mukhopadhaya et al. 2009) and has been estimated to occur in as many as $46.4 \%$ of those treated with clozapine (Anil et al. 2002, Galvez-Buccolini et al. 2004). If this were to be the case, then we might infer that the obsessions and compulsions in our cases were not representative of archetypal OCD. This hypothesis, however, has yet to be substantiated in the context of a prospectively designed, controlled longitudinal study and is hard to integrate with other published data showing that antipsychotics produce anti-obsessional effects in schizophrenia and that adjunctive antipsychotics are clinically effective in treatment-resistant OCD. Moreover, we note that OCS were noted in patients with schizophrenia long before the advent of psychotropic medications (Berrios, 1989) and, as far back as Bleuler (1911), the similarities of delusions and obsessions were noted. All of our patients were medicated with clozapine (i.e. regardless of whether or not they exhibited OCD symptoms).

Other explanations for the high rates of OCD observed in clozapine-treated patients have also been put forward, including: that OCD is a naturally occurring sub-syndrome within the schizophrenia spectrum, i.e. schizo-obsessives who have a genetic liability for both schizophrenia and OCD (Poyurovsky et al. 2003, 2004; Kayahan et al. 2005); that treatment with atypical antipsychotics (such as clozapine) may unmask OCD previously hidden by schizophrenic symptoms (Ertugrul \& Demir 2005); or that some, as yet unidentified, factor may predispose individuals both to OCD and to schizophrenia. Thus, greater levels of illness co-morbidity might be predicted in such patients. In a cross-sectional survey of 59 cases of clozapine-treated illness, Mukhopadhaya et al. (2009) did not find that the point prevalence of OCD (24\%) was elevated in clozapine-treated cases compared with other antipsychotics. We note that inclusion of a matched OCD control group in this study might have shed light on this question by helping tease apart different neuro-cognitive aspects of these disorders.

Schizo-obsessives made significantly more ID-ED errors compared with a matched group with schizophrenia. Inspection of ID-ED errors at each of the nine stages showed schizo-obsessives separated from schizophrenics at the two most difficult stages of attentional set-shift, i.e. EDS, in which the relevant stimulus dimension alters, and EDS reversal, in which a rule learnt needs to be inhibited and reversed. The EDS stage is the critical stage of the ID/ED and is thought to represent the category shift in the Wisconsin Card Sorting Test (WCST) (Downes et al. 1989). The number of errors made at this stage represents attentional setshifting ability.

There was no evident relationship between ED impairment and schizophrenia or OCD symptom severity, and the deficits endured despite treatment with SSRI in $74 \%$ of cases with schizo-OCD, implying trait rather than state-marker status. fMRI research evidence suggests ED shifting in normal volunteers involves ventro-lateral prefrontal cortex circuits, which are believed to subserve 'cognitive flexibility' or 'cognitive inhibition' (Hampshire \& Owen, 2006). 
Table 5. Mean effect sizes of WCST categories completed from neuropsychological studies in schizo-OCD

\begin{tabular}{llc}
\hline Study & Samples & Effect size $(d)$ \\
\hline Lysaker et al. (2000) & Sz with OCS $(n=21)$, Sz $(n=25)$ & 0.00 \\
Lysaker et al. (2002) & Sz/schizo-affective with OCD $(n=11)$, & 0.35 \\
& $\quad$ without OCD $(n=52)$ & \\
Hermesh et al. (2003) & Sz-obs $(n=21)$, Sz $(n=19)$ & -0.09 \\
Whitney et al. (2004) & Sz-obs $(n=26)$, Sz $(n=28)$ & 0.08 \\
Ongur \& Goff (2005) & Sz-obs $(n=14)$, Sz $(n=79)$ & 1.06 \\
\hline
\end{tabular}

WCST, Wisconsin Card Sorting Test; schizo-OCD, schizophrenia and co-morbid obsessive compulsive disorder.

One can hypothesize how deficits in cognitive flexibility are linked to OCD phenomenology (i.e. obsessions or compulsions) as OCD patients are unable to shift from one thought or action to another or stop thoughts entering their head unbidden. Hence, cognitive inflexibility may represent a candidate endophenotype, i.e. an inherited vulnerability factor for schizo-OCD. Evidence that set-shifting may act as a neuro-cognitive endophenotype for schizophrenia per se comes largely from the WCST and is somewhat mixed, with unaffected relatives of individuals with schizophrenia not consistently manifesting poorer WCST performance than controls (Kremen \& Hoff, 2004). Similar negative findings from the ID-ED task in schizophrenic patients without documented OCD, recently reported by Ceaser et al. (2008), cast further doubt on ED shift deficits representing a familial trait marker for schizophrenia and imply such impairment relates to the co-occurrence of OCD.

This is the first study to examine ID-ED shifting in schizo-OCD. Impairment in ED set-shifting has been identified in tic-free OCD patients with predominantly washing and checking rituals and their unaffected first-degree relatives (Chamberlain et al. 2006b, $2007 a, b)$ and in patients with OCD plus obsessive compulsive personality disorder (Fineberg et al. 2007). Our findings are also consistent with results reported by Watkins et al. (2005), who identified selective ED deficits in OCD outpatients, and Veale et al. (1996), who found that OCD in-patients made more errors than controls on multiple stages of the ID-ED task. Further exploration of ID-ED performance in unaffected relatives of schizo-OCD probands may help clarify whether ED shifting represents an inherited vulnerability factor for an obsessive compulsive syndrome occurring in combination with schizophrenia.

Previous neuropsychological studies into schizoOCD have used the WCST as a test of attentional setshifting. A survey of the literature identified five relevant studies (totalling 80 schizo-obsessives and
149 schizophrenics; see Table 5) and the effect sizes reveal that schizo-obsessives sort fewer WCST categories than schizophrenics. Nevertheless, the mean effect size was small ( $d=0.20,95 \%$ confidence interval -0.02 to 0.50$)$ and non-significant, almost certainly because of the limited number of studies $(K=5)$ in the meta-analysis and because only one study produces a large effect (Ongur \& Goff, 2005).

The WCST can be criticized for its non-specific nature, tapping a wide range of other neuro-cognitive processes aside from attentional set-shifting, such as error-based learning, feedback processing and working memory (Laws, 1999). In this respect, we believe the ID-ED task represents a more specific test of attentional set-shifting that has been anatomically localized, at least in normal volunteers, to circuits involving the ventro-lateral prefrontal cortex (Hampshire \& Owen, 2006). The findings from this small meta-analysis, however, suggest a similar pattern of deficits to that found in our study, thereby providing further support for a more severe setshifting deficit signifying a cognitive marker in schizoOCD patients. Nevertheless, we also note that like WCST performance, performance on the ID-ED setshifting task is related to current intellectual functioning (for a review, see Laws 1999). Although our two patient groups were matched on estimated premorbid NART IQ, we cannot eliminate the possibility that the schizo-obsessive group had undergone a greater deterioration in current IQ.

Tics, which commonly occur together with OCD, were a clinical sign that differentiated schizo-OCD from schizophrenia with higher scores for motor tics observed on the YGTSS, representing greater severity of tic-related disorder compared with the schizophrenia group. Additionally, we found a trend difference for abnormal involuntary movements being greater in the schizo-obsessive group. Our findings, therefore, accord with previous studies that have found evidence for more severe motor impairment in 
the schizo-OCD profile (Kruger et al. 2000; Ohta et al. 2003; Mukhopadhaya et al. 2009).

What do our results say about the nosology of schizo-OCD? Compared with patients with schizophrenia, patients with schizo-OCD showed more severe deficits limited to domains previously reported for non-co-morbid OCD. Our study, therefore, suggests a neuro-cognitive overlap between OCD and schizophrenia and a 'true' co-morbidity of two separate disorders. Application of a wider range of tests in future studies may identify additional neurocognitive features that are unique to schizo-OCD, which would challenge this concept. Our results also suggest that the neuro-cognitive profile associated with tic-related OCD co-morbid with schizophrenia resembles that reported for the 'archetypal' form of OCD (washers and checkers without tics) (Chamberlain et al. 2006a, 2007a, b), i.e. ED shifting appears a fundamental aspect of OCD in a variety of phenotypic forms. Such an overlap has important implications for understanding the neurobiology of this complex, disabling disorder and generating new pharmacological and psychological treatment targets. Future research, using larger cohorts, may further tap the richness of schizo-OCD pathology by expanding into other key neuropsychological areas known to be implicated in schizophrenia and OCD, such as memory, motor impulsivity and affective processing.

\section{Conclusion}

Using specific tests of neuro-cognitive processing, we have demonstrated that schizophrenia patients with OCD exhibited significantly greater impairment on a task of attentional set-shifting (extra-dimensional set-shift) compared with a matched group of schizophrenia patients without OCD. Consistent with previous studies, our findings implicate impaired set-shifting, representing cognitive inflexibility, as a candidate trait marker for schizo-OCD.

\section{Acknowledgements}

We would like to thank senior nurse Karen Reddy and administrators Chris O'Brien and Kim Fox from the Clozapine clinic in Welwyn Garden City for their contribution to the smooth running of the study; and to Dr David Hart and Cambridge Cognition for their support in providing CANTAB for the project. Devina Patel conducted this research in part fulfilment of the MSc Research Methods in Cognitive Neuropsychology at the University of Hertfordshire.

\section{Declaration of interest}

None.

\section{References}

Anil AE, Turgut IT, Kabakci E, Rezaki M, Gogus A (2002). The characteristics, treatment response, safety, and concominant medication use of patients receiving clozapine treatment. European Neuropsychopharmacology $\mathbf{1 2}$ (Suppl.), 322.

Aoyama F, Iida J, Inoue M, Iwasaka H, Sakiyama S, Hata K, Kishimoto T (2000). Brain imaging in childhood- and adolescent-onset schizophrenia associated with obsessivecompulsive symptoms. Acta Psychiatrica Scandinavica (Suppl.) 102, 32-37.

Berman I, Kalinowski A, Berman SM, Lengua J, Green AI (1995). Obsessive and compulsive symptoms in chronic schizophrenia. Comprehensive Psychiatry 36, 6-10.

Berman I, Merson A, Viegner B, Losonczy MF, Pappas D, Green AI (1998). Obsessions and compulsions as a distinct cluster of symptoms in schizophrenia:

a neuropsychological study. Journal of Nervous and Mental Disease 186, 150-156.

Bermanzohn PC, Porto L, Arlow PB, Axelrod S, Sastri G, Stronger R, Pollack S, Siris S (1997). Obsessions and delusions: separate and distinct or overlapping? CNS Spectrums 2, 58-61.

Bermanzohn PC, Porto L, Arlow PB, Pollack S, Stronger R, Siris SG (2000). Hierarchial diagnosis in chronic schizophrenia: a clinical study co-occurring syndromes. Schizophrenia Bulletin 26, 517-525.

Berrios GE (1989). Obsessive-compulsive disorder: its conceptual history in France during the 19th century. Comprehensive Psychiatry 30, 283-295.

Bland RC, Newman SC, Orn H (1987). Schizophrenia: lifetime comorbidity in a community sample. Acta Psychiatrica Scandinavica (Suppl.) 75, 383-391.

Bleuler E. (1911). The Fundamental Symptoms of Dementia Praecox or the Group of Schizophrenias. International Universities Press: New York.

Braw Y, Bloch Y, Mendelovich S, Ratzoni G, Gal G, Harari H, Tripto A, Levkovitz Y (2008). Cognition in young schizophrenia outpatients: Comparison of first-episode with multi-episode patients. Schizophrenia Bulletin 34, 544-554.

Buchanan RW, Heinrichs DW (1989). The Neurological Evaluation Scale (NES): a structured instrument for the assessment of neurological signs in schizophrenia. Psychiatry Research 27, 335-350.

Byerly M, Goodman W, Acholonu W, Bugno R, Rush AJ (2005). Obsessive compulsive symptoms in schizophrenia: frequency and clinical features. Schizophrenia Research 76, 309-316.

Ceaser AE, Goldberg TE, Egan MF, McMahon RP, Weinberger DR, Gold JM (2008). Set-shifting ability and schizophrenia : a marker of clinical illness or an intermediate phenotype? Biological Psychiatry 64, 782-788.

Chamberlain SR, Blackwell AD, Fineberg NA, Robbins TW, Sahakian BJ (2006a). Motor inhibition and cognitive flexibility in obsessive-compulsive disorder and trichotillomania. American Journal of Psychiatry 163, 1282-1284.

Chamberlain SR, Blackwell AD, Fineberg NA, Robbins TR and Sahakian BJ (2006b). Strategy implementation in 
obsessive-compulsive disorder and trichotillomania Psychological Medicine 36, 91-97.

Chamberlain SR, Fineberg NA, Blackwell AD, Clark L, Robbins TW, Sahakian BJ (2007a). A neuropsychological comparison of obsessive-compulsive disorder and trichotillomania Neuropsychologia 45, 654-662.

Chamberlain SR, Fineberg NA, Menzies L, Blackwell AD, Bullmore ET, Robbins TW, Sahakian BJ (2007b). Impaired cognitive flexibility and motor inhibition in unaffected first-degree relatives of patients with obsessive-compulsive disorder. American Journal of Psychiatry 164, 335-338.

Crino R, Slade T, Andrews G (2005). The changing prevalence and severity of obsessive-compulsive disorder criteria from DSM-III to DSM-IV. American Journal of Psychiatry 162, 876-882.

Downes JJ, Roberts AC, Sahakian BJ, Evenden JL, Morris RG, Robbins TW (1989). Impaired extra-dimensional shift performance in medicated and unmedicated Parkinson's disease: Evidence for a specific attentional dysfunction. Neuropsychologia 27, 1329-1343.

Eisen JL, Beer DA, Pato MT, Venditto TA, Rasmussen SA (1997). Obsessive-compulsive disorder in patients with schizophrenia and schizoaffective disorder. American Journal of Psychiatry 154, 271-273.

Elliott R, McKenna PJ, Robbins TW, Sahakian BJ (1995). Neuropsychological evidence for frontostriatal dysfunction in schizophrenia Psychological Medicine 25, 619-630.

Elliott R, McKenna PJ, Robbins TW, Sahakian BJ (1998). Specific neuropsychological deficits in schizophrenic patients with preserved intellectual function. Cognitive Neuropsychiatry 3, 45-70.

Ertugrul A, Demir B (2005). Clozapine-induced tardive dyskinesia: a case report. Progress in NeuroPsychopharmacology \& Biological Psychiatry 29, 633-635.

Fabisch K, Fabisch H, Langs G, Huber HP, Zapotoczky HG (2001). Incidence of obsessive-compulsive phenomena in the course of acute schizophrenia and schizoaffective disorder. European Psychiatry 16, 336-341.

Fenger MM, Gade A, Adams KH, Hansen ES, Bolwig TG, Knusden GM (2005). Cognitive deficits in obsessivecompulsive disorder on tests of frontal lobe functions. Nordic Journal of Psychiatry 59, 39-44.

Fenton WS, McGlashan TH (1986). The prognostic significance of obsessive-compulsive symptoms in schizophrenia. American Journal of Psychiatry 143, 437-441.

Fineberg NA, Gale T, Sivakumaran T (2006). A review of antipsychotics in treatment resistant obsessive compulsive disorder (OCD). Journal of Psychopharmacology 20, 97-103.

Fineberg NA, Sharma P, Sivakumaran T, Sahakian B, Chamberlain SR (2007). Does obsessive-compulsive personality disorder belong within the obsessivecompulsive spectrum? CNS Spectrums 12, 467-482.

Fioravanti M, Carlone O, Vitale B, Cinti ME, Clare L (2005). A meta analysis of cognitive deficits in adults with a diagnosis of schizophrenia. Neuropsychology Review 15, 73-95.

Fireman B, Koran LM, Leventhal JL, Jacobson A (2001). The prevalence of clinically recognized obsessive-compulsive disorder in a large health maintenance organization. American Journal of Psychiatry 158, 1904-1910.

Galvez-Buccollini JA, Fiestas F, Herrera P, Vega-Dienstmaier JM, Guimas B, Mazzotti G (2004). Obsessive-compulsive symptoms in schizophrenia during treatment with clozapine and conventional antipsychotic drugs. Actas Españolas de Psiquiatria 32, 211-215.

Goldstein JM, Goodman JM, Seidman LJ, Kennedy DN, Makris N, Lee H, Tourville J, Cavines Jr. VS, Faraone SV, Tsuang MT (1999). Cortical abnormalities in schizophrenia identified by structural magnetic resonance imaging. Archives of General Psychiatry 56, 537-547.

Goodman WK, Price LH, Rasmussen SA, Mazure C, Delgado P, Heninger GR, Charney DS (1989a). The Yale-Brown obsessive compulsive scale. II. Validity. Archives of General Psychiatry 46, 1012-1016.

Goodman WK, Price LH, Rasmussen SA, Mazure C, Fleischmann RL, Hill CL, Heninger GR, Charney DS (1989b). The Yale-Brown obsessive-compulsive scale. I. Development, use and reliability. Archives of General Psychiatry 46, 1006-1011.

Guy W (1976). ECDEU Assessment Manual for Psychopharmacology (Revised). US Department of Health, Education and Welfare: Bethesda, MD.

Hampshire A, Owen AM (2006). Fractionating attentional control using event-related fMRI. Cerebral Cortex 16, 1279-1289.

Haro JM, Kamath SA, Ochoa S, Novick D, Rele K, Fargas A, Rodriguez MJ, Rele R, Orta J, Kharbeng A, Araya S, Gervin M, Alonso J, Mavreas V, Lavrentzou E, Liontos N, Gregor K, Jones PB (2003). The Clinical Global Impression-Schizophrenia scale: a simple instrument to measure the diversity of symptoms present in schizophrenia. Acta Psychiatrica Scandinavica (Suppl.) 416, 16-23.

Hermesh H, Weizman A, Gur S, Zalsman G, Shiloh R, Zohar J, Gross-Isseroffa R (2003). Alternation learning in OCD/schizophrenia patients European Neuropsychopharmacology 13, 87-91.

Hill K, Mann L, Laws KR, Stephenson CME, Nimmo-Smith I, McKenna PJ (2004). Hypofrontality in schizophrenia : a meta-analysis of functional imaging studies. Acta Psychiatrica Scandinavica 110, 1-14.

Huppert JD, Smith TE (2005). Anxiety and schizophrenia: the interaction of subtypes of anxiety and psychotic symptoms. CNS Spectrum 10, 721-731.

Hutton SB, Murphy FC, Joyce EM, Rogers RD, Cuthbert I, Barnes TRE, McKenna PJ, Sahakian BJ, Robbins TW (2002). Decision making deficits in patients with first episode and chronic schizophrenia. Schizophrenia Research 55, 249-257.

Hutton SB, Puri BK, Duncan L-J, Robbins TW, Barnes TRE, Joyce EM (1998). Executive function in first-episode schizophrenia. Psychological Medicine 28, 463-473.

Hwang MY, Morgan JE, Losconzcy MF (2000). Clinical and neuropsychological profiles of obsessive-compulsive schizophrenia: a pilot study. Journal of Neuropsychiatry and Clinical Neuroscience 12, 91-94. 
Hwang MY, Opler LA (1994). Schizophrenia with obsessive-compulsive features: assessment and treatment. Psychiatric Annals 24, 468-472.

Jazbec S, Pantelis C, Robbins TW, Weickert T, Weinberger DR, Goldberg MC (2007). Intra-dimensional/ extra-dimensional set-shifting performance in schizophrenia: impact of distractors. Schizophrenia Research 89, 339-349.

Joyce EM, Hutton SB, Mutsatsa S, Gibbins H, Webb E, Paul S, Robbins TW, Barnes TRE (2002). Executive dysfunction in first-episode schizophrenia and relationship to duration of untreated psychosis: the West London Study. British Journal of Psychiatry 181 (Suppl. 43), 38-44.

Karno M, Golding JM, Sorenson SB, Burnam MA (1988). The epidemiology of obsessive-compulsive disorder in five US communities. Archives of General Psychiatry 45, 1094-1099.

Kayahan B, Ozturk O, Veznedaroglu B, Eraslan D (2005). Obsessive compulsive symptoms in schizophrenia: prevalence and clinical correlates. Psychiatry and Clinical Neurosciences 59, 291-295.

Kremen WS, Hoff AL (2004). Neuro-cognitive deficits in the biological relatives of individuals with schizophrenia. In Early Clinical Intervention and Prevention in Schizophrenia (ed. W. S. Stone, S. V. Faraone, M. T. Tsuang), pp. 133-158. Totowa, NJ: Humana Press.

Kruger S, Braunig P, Hoffler J, Shugar G, Borner I, Langkrar J (2000). Prevalence of obsessive-compulsive disorder in schizophrenia and significance of motor symptoms. Journal of Neuropsychiatry and Clinical Neuroscience 12, 16-24.

Laws KR (1999). A meta-analytic review of Wisconsin Card Sort studies in schizophrenia: General intellectual deficit in disguise? Cognitive Neuropsychiatry 4, 1-30.

Leckman JF, Riddle MA, Hardin MT, Ort SI, Swartz KL, Stevenson J, Cohen DJ (1989). The Yale Global Tic Severity Scale: initial testing of a clinician-rated scale of tic severity. Journal of the American Academic Child Adolescent Psychiatry 28, 566-573.

Levaux M-N, Potvin S, Sepehry AA, Sablier J, Mendrek A, Stip E (2007). Computerized assessment of cognition in schizophrenia: promises and pitfalls of CANTAB. European Psychiatry 22, 104-115.

Lindenmayer JP, Vakharia M, Kanofsky D (1990). Fluoxetine in chronic schizophrenia [Letter]. Journal of Psychopharmacology 10, 76.

Lysaker PH, Bryson GJ, Marks KA, Greig TC, Bell MD (2002). Association of obsessions and compulsions in schizophrenia with neurocognition and negative symptoms. Journal of Neuropsychiatry and Clinical Neurosciences 14, 449-453.

Lysaker PH, Lancaster RS, Nees M, Davis LW (2004). Patterns of obsessive compulsive symptoms and social function in schizophrenia. Psychiatry Research 125, 139-146.

Lysaker PH, Marks KA, Picone JJ, Rollins AL, Fastenau P, Bond GR (2000). Obsessive and compulsive symptoms in schizophrenia: Clinical and neuro-cognitive correlates. Journal of Nervous and Mental Disease 188, 78-83.

Montgomery SA, Åsberg M (1979). A new depression scale designed to be sensitive to change. British Journal of Psychiatry 134, 382-389.
Mukhopadhaya K, Krishnaiah R, Taye T, Nigam A, Bailey AJ, Sivakumaran T, Fineberg NA (2009). Obsessive-compulsive disorder in UK clozapine-treated schizophrenia and schizoaffective disorder: a cause for clinical concern. Journal of Psychopharmacology 23, 6-13.

Murphy FC, Rubinsztein JS, Michael A, Rogers RD, Robbins TW, Paykel ES, Sahakian BJ (2001). Decisionmaking cognition in mania and depression. Psychological Medicine 31, 679-693.

Murphy FC, Sahakian BJ, Rubinsztein JS, Michael A, Rogers RD, Robbins TW, Paykel ES (1999). Emotional bias and inhibitory control processes in mania and depression. Psychological Medicine 29, 1307-1321.

Myers JK, Weissman MM, Tischler GL, Holzer III CE, Leaf PJ, Orvaschel H, Anthony JC, Boyd JH, Burke Jr. JD, Kramer M (1984). Six-month prevalence of psychiatric disorders in three communities 1980 to 1982. Archives of General Psychiatry 41, 959-967.

Nelson HE (1982). The National Adult Reading Test (NART). Test Manual. Windsor: NFER-Nelson.

Niehaus DJ, Koen L, Muller J, Laurent C, Stein DJ, Lochner C, Seedat S, Mbanga I, Deleuze JF, Mallet J, Emsley RA (2005). Obsessive compulsive disorder - prevalence in Xhosa-speaking schizophrenia patients. South African Medical Journal 95, 120-122.

Nielen MM, den Boer JA (2003). Neuropsychological performance of OCD patients before and after treatment with fluoxetine: evidence for persistent cognitive deficits. Psychological Medicine 33, 917-925.

Ohta M, Kokai M, Morita Y (2003). Features of obsessive compulsive disorder in patients primarily diagnosed with schizophrenia. Psychiatry and Clinical Neurosciences 57, 67-74.

Ongur D, Goff DC (2005). Obsessive-compulsive symptoms in schizophrenia: associated clinical features, cognitive function and medication status. Schizophrenia Research 75, 349-362.

Pantelis C, Barber FZ, Barnes TRE, Nelson HE, Owen AM, Robbins TW (1999). Comparison of set-shifting ability in patients with chronic schizophrenia and frontal lobe damage. Schizophrenia Research 37, 251-270.

Pantelis C, Barnes TRE, Nelson HE, Tanner S, Weatherly L, Owen A, Robbins TW (1997). Frontal-striatal cognitive deficits in patients with chronic schizophrenia. Brain 120, 1823-1843.

Poyurovsky M, Dorfman-Etrog P, Hermesh H, Munitz H, Tollefson GD, Weizman A (2000). Beneficial effect of olanzapine in schizophrenic patients with obsessive-compulsive symptoms. International Clinical Psychopharmacology 15, 169-173.

Poyurovsky M, Faragian S, Pashinian A, Levi A, Viosburd A, Stryjer R, Weizman R, Fuchs C, Weizman A (2007). Neurological soft signs in schizophrenia patients with obsessive-compulsive disorder. Journal of Neuropsychiatry and Clinical Neurosciences 19, 145-150.

Poyurovsky M, Fuchs C, Faragian S, Kriss V, Weisman G, Pashinian A, Weizman R, Weizman A (2006). Preferential aggregation of obsessive-compulsive spectrum disorders in schizophrenia patients with obsessive-compulsive disorder. Canadian Journal of Psychiatry 51, 746-754. 
Poyurovsky M, Fuchs C, Weizman A (1999a).

Obsessive-compulsive disorder in patients with first-episode schizophrenia. American Journal of Psychiatry 156, 1998-2000.

Poyurovsky M, Hramenkov S, Isakov V (2001). Obsessive-compulsive disorder in hospitalized patients with chronic schizophrenia. Psychiatry Research 102, 49-57.

Poyurovsky M, Isakov V, Harmonikov S, Modai I, Rachberger B, Schneidman M, Weizman A (1999b). Fluvoxamine treatment of obsessive compulsive symptoms in schizophrenic patients: an add-on open study. International Clinical Psychopharmacology 14, 95-100.

Poyurovsky M, Kriss V, Weisman G, Faragian S, Kurs R, Schneidman M, Fuchs C, Weizman A, Weizman R (2003). Comparison of clinical characteristics and comorbidity in schizophrenia patients with and without obsessivecompulsive disorder: Schizophrenic and OC symptoms in schizophrenia. Journal of Clinical Psychiatry 64, 1300-1307.

Poyurovsky M, Weizman A, Weizman R (2004). Obsessive-compulsive disorder in schizophrenia : clinical characteristics and treatment. CNS Drugs 18, 989-1010.

Purcell R, Maruff P, Kyrios M, Pantelis C (1998a). Cognitive deficits in obsessive-compulsive disorder on tests of fronto-striatal function. Biological Psychiatry 43, 348-357.

Purcell R, Maruff P, Kyrios M, Pantelis C (1998b). Neuropsychological deficits in obsessive-compulsive disorder A comparison with unipolar depression, panic disorder and normal controls. Archives of General Psychiatry 55, 415-423.

Rahman S, Sahakian BJ, Hodges JR, Rogers RD, Robbins TW (1999). Specific cognitive deficits in mild frontal variant frontotemporal dementia. Brain 122, 1469-1493.

Rajkumar RP, Reddy YC, Kandavel T (2008). Clinical profile of 'schizo-obsessive' disorder: a comparative study. Comprehensive Psychiatry 49, 262-268.

Rogers RD, Everitt BJ, Baldacchino A, Blackshaw AJ, Swainson R, Wynne K, Baker NB, Hunter J, Carthy T, Booker E, London M, Deakin JFW, Sahakian BJ, Robbins TW (1999). Dissociable deficits in the decision-making cognition of chronic amphetamine abusers, opiate abusers, patients with focal damage to prefrontal cortex, and tryptophan-depleted normal volunteers: Evidence for monoaminergic mechanisms. Neuropsychopharmacology 20, 322-339.

Rosen I (1957). The clinical significance of obsessions in schizophrenia. Journal of Mental Science 103, 773-785.

Sevincok L, Akoglu A, Topaloglu B, Aslantas H (2004). Neurological soft signs in schizophrenic patients with obsessivecompulsive disorder. Psychiatry and Clinical Neurosciences 58, 274-279.

Shamay-Tsoory SG, Shur S, Harari H, Levkovitz Y (2007). Neuro-cognitive basis of impaired empathy in schizophrenia. Neuropsychology 21, 431-438.

Sheehan DV, Harnett-Sheehan K, Raj BA (1996). The measurement of disability. International Clinical Psychopharmacology 3, 89-95.

Sheehan DV, Lecrubier Y, Sheehan KH, Amorim P, Janavs J, Weiller E, Hergueta T, Baker R, Dunbar GC (1998). The Mini-International Neuropsychiatric Interview (M.I.N.I.): the development and validation of a structured diagnostic psychiatric interview for DSM-IV and ICD-10. Journal of Clinical Psychiatry 59 (Suppl.) 20, 34-57.

Simpson GM, Angus JW (1970). A rating scale for extrapyramidal side effects. Acta Psychiatrica Scandinavica (Suppl.) 212, 11-19.

Tibbo P, Kroetsch M, Chue P, Warneke L (2000). Obsessive-compulsive disorder in schizophrenia. Journal of Psychiatry Research 34, 139-146.

Tyson PJ, Laws KR, Roberts KH, Mortimer AM (2004). Stability of set-shifting and planning abilities in patients with schizophrenia. Psychiatry Research 129, 229-239.

van den Heuvel OA, Veltman DJ, Groenewegen HJ, Cath DC, van Balkom AJ, van Hartskamp J, Barkhof F, van Dyck R (2005). Frontal-striatal dysfunction during planning in obsessive-compulsive disorder. Archives of General Psychiatry 62, 301-309.

Veale DM, Sahakian BJ, Owen AM, Marks IM (1996). Specific cognitive deficits in tests sensitive to frontal lobe dysfunction in obsessive-compulsive disorder.

Psychological Medicine 26, 1261-1269.

Watkins LHA, Sahakian BJ, Robertson M, Veale DM, Rogers RD, Pickard KM, Aitken MR, Robbins TW (2005). Executive function in Tourette's syndrome and obsessive-compulsive disorder. Psychological Medicine 35, 571-582.

Wells A, Cartwright-Hatton S (2004). A short form of the Metacognition Questionnaire: properties of the MCQ-30. Behavior, Research and Therapy 42, 385-396.

Whitney KA, Fastenau PS, Evans JD, Lysaker PH (2004). Comparative neuropsychological function in obsessive-compulsive disorder and schizophrenia with and without obsessive-compulsive symptoms. Schizophrenia Research 69, 75-83.

Zohar J, Birkett M, Wood AJ (1993). A double-blind, placebo-controlled study of fluoxetine in patients with DSM-III-R obsessive-compulsive disorder. The Lilly European OCD Study Group European Neuropsychopharmacology 3, 143-152. 